To be published as:

BRUGHMANS, T. 2010: Connecting the dots : towards archaeological network analysis. Oxford Journal of Archaeology.

\title{
TOM BRUGHMANS
}

\section{CONNECTING THE DOTS: TOWARDS ARCHAEOLOGICAL NETWORK ANALYSIS}

Summary. In recent years network analysis has been applied in archaeological research to examine the structure of archaeological relationships of whatever sort. However, these archaeological applications share a number of issues concerning 1) the role of archaeological data in networks; 2) the diversity of network structures, their consequences and their interpretation; 3) the critical use of quantitative tools; 4) the influence of other disciplines, especially sociology. This article concerns a deconstruction of past archaeological methods for examining networks. Through a case-study of Roman table wares in the Eastern Mediterranean, the article will highlight a number of issues with network analysis as a method for archaeology. It urges caution with the uncritical application of network analysis methods developed in other disciplines and applied to archaeology. However, it stresses the potential benefits of network analysis for the archaeological discipline and acknowledges the need for developing a specifically archaeological network analysis, which should be based on relational thinking and can be expanded with an archaeological toolset for quantitative analysis.

\section{INTRODUCTION}

The main goal of network analysis is detecting and interpreting patterns of relationships between subjects of research interest. These can be anything from individuals and objects to countries or communities. Network analysis is rooted in a branch of mathematics called graph theory (Barnes and Harary 1983; Harary 1969; Harary and Norman 1953), from which it adopts techniques for 
identifying, examining and visualising patterns of relationships. A graph represents the structure of a network of relationships, while a network consists of a graph and additional information on the vertices or the lines of the graph (Nooy et al. 2005, 6-7). It consists of a set of vertices (also called points or nodes) which represent the smallest units in the analysis, and a set of lines (or ties) between these vertices which represent their relationships.

Contrary to other disciplines like sociology, in which ideas from graph theory were rapidly adopted and where social network analysis has developed into a major paradigm (Freeman 2004; Wasserman and Faust 1994), network analysis has only recently become popular as a method for archaeological research. As a result the first generation of archaeological applications is very heterogeneous, each adopting their network methodology and terminology from a largely different set of authors. This is illustrated in the citation network of references from relevant archaeological articles (Fig. 1). As will be discussed below, differences in method are not necessarily problematic as network analysis itself is a collective term, combining a number of ideas and quantitative tools from several disciplines. The danger exists, however, that the full diversity of network analysis will not find its way into the archaeological discipline if archaeological applications maintain their current correct but restricted view of the method.

This article aims at evaluating past archaeological applications of network analysis, focusing on some issues these have in common. Through a case-study of table ware distributions in the Roman East the source of these issues and the potential of network analysis as a method for archaeology will be explored.

\section{ARCHAEOLOGICAL APPLICATIONS OF NETWORK ANALYSIS}

\section{Network types and structural consequences}

As a first example Sindbæk's (2007) article on the emergence of towns in early Viking Age 
Scandinavia is discussed. Based on the relative volume of imported goods and raw materials, the author suggests a hierarchy of sites. He adopts a network perspective to understand the distinction between a few towns active in long-distance trade (described as nodal points) and the many local markets. Towns with a higher ratio of imported materials are seen as being "linked by communications and activities of a very similar scale and nature" (Sindbæk 2007, 123) driven by long distance-trade. The local markets, on the other hand, were "served by local traffic and doubtlessly communicated with the nodal points, but not with the long-distance traffic that travelled between them" (Sindbæk 2007, 127). The resulting system of trade connections is explained in light of two conceptions of networks. Firstly, the system is considered to be similar to a scale-free network, as defined by Barabàsi and Albert (1999), in which continuously added new vertices attach preferentially to those nodes that are already well connected. Secondly, Sindbæk refers to Latour's (2005) actor-network theory to stress the heterogenous processes that shape and evolve networks.

Although there can be no doubt that the picture Sindbæk painted, of a dynamic network of towns in which a few urban centres emerged due to a diversity of processes, offers a highly informative and innovative view of his research topic, some issues should be raised concerning his adoption and use of network models. First and foremost, Sindbæk's network perspective is based on two conceptions of networks that are adopted without any critique, nor does the author compare them with other popular network types. Indeed, there is no reason why the Scandinavian towns could not be seen as a small-world (Buchanan 2002; Milgram 1967; Watts and Strogatz 1998; Watts 1999) connecting to other small-worlds through a limited number of long-distance trade connections (e.g. Fig 2). Barabàsi and Albert's (1999, 510) statement that in a small-world network nodes with high connectivity are practically absent does not exclude this option, as the group of sites with imported materials could have formed the small number of bridges to other small-worlds. As such, the 
assemblages of these towns would not be explained as a result of having more trade connections than local markets, but rather through their position as a necessary go-between in long-distance trade. This criticism is not meant to suggest that Sindbæk's model does not fit the archaeological data or that it is improbable. It merely stresses the need to discuss other possible models, a need which becomes increasingly critical in light of the next issue. This second issue concerns the structural consequences of adopting a certain network type. Through mechanisms of growth and preferential attachment, a small number of nodes will be far more connected than others in a scalefree network (Barabàsi and Albert 1999). Such a specific topology has direct implications for the processes underlying it, like the transportation of materials, the spread of religious ideas or the enforcement of political power. These processes would largely take place between the highly connected nodes, and they would only reach the larger number of less connected nodes through these vertices. In a small-world network, on the other hand, nodes within the same small-world are more often directly connected to each other, while only processes involving other small-worlds (e.g. long-distance trade) would go over the bridging nodes. The identification of a specific network model is an interpretation that has direct consequences for the workings and evolution of a network. It should therefore be thoroughly discussed and, if possible, validated archaeologically.

\section{Archaeological data, scaling and quantitative tools}

The second archaeological application of network analysis under discussion is Isaksen's (2008) analysis of transport networks in Roman Baetica. Based on the Antonine Itineraries and the Ravenna Cosmography, networks were created in which towns formed the nodes and transport routes were represented by the connections between nodes. Subsequently, the positions of towns on these networks were explored. For this purpose, the closeness centrality and betweenness centrality measures (Freeman 1977) were used. Closeness centrality was defined as "the ease with which a node can reach, or be reached by, any other node on the network" and betweenness centrality as 
"the probability that a node will be passed by traffic travelling along the shortest route between two other nodes on the network" (Isaksen 2008, §13-§14). The results of these measures allowed the author to make some cautious statements on the function of towns as go-betweens and major starting/ending points in the transport network of the region. However, Isaksen was very aware of the limitations of his data. He used network analytical tools to examine structural aspects of an incomplete set of route descriptions, made for an unclear purpose by an unknown author. In this case a network analysis will reveal more about the nature of the dataset than it will about physical travel conditions in the past. This method is not insensitive to the limitations of archaeological data and should definitely not be treated as such.

The Antonine itineraries formed the basis for another archaeological application of network analysis. Shawn Graham (2006b) used a social network analysis method to examine how these itineraries presented geographical space to the reader or traveler, in order to reflect on the Roman perception of space. The itineraries were transformed into a network, consisting of routes of travel between places throughout the empire, and the structure of parts of the empire-wide network was explored. The shortest, longest and average path lengths between places in regions were calculated, suggesting a stronger homogeneity within regions (smaller path lengths) than for the empire as a whole (Graham 2006b, 50). Secondly, the cohesion of travel routes in regions and the empire was determined. The author defined cohesion as "the proportion of links that exist in the network compared to a network with the same number of nodes, where the nodes are all completely connected to each other" (Graham 2006b, 50-51). A significant difference in coherence was observed between Gaul on the one hand and Italy, Iberia and Britain on the other, giving rise to the idea that travel can be more easily disrupted in less cohesive regions. To explore the perception of disruption a fragmentation curve was plotted (Graham 2006b, fig. 3), indicating how a region's travel network would fall apart if an increasing number of places were perceived to be unreachable. 
This network was subsequently brought to life through an agent-based simulation to explore the speed of the dissemination of information over parts of the travel network.

Like Isaksen, Graham acknowledges that his network analysis method explores the structure of his data, rather than a system of physical routes. Although both authors are primarily interested in the structure of a similar dataset, they use strongly differing methods. Isaksen focuses on the topological position of individual nodes, while Graham is more concerned with average measures of parts of the network and the network as a whole. However, both authors interpret their results similarly, focusing on the implications of structural features for communication and transportation. Exploring such themes on the level of towns or that of the entire system are both informative approaches, but restricting an analysis to one or the other has immediate consequences for the depth to which one can explore a dataset. Moreover, it is unclear why the authors have decided to perform their analyses on these scales, as in both cases comparing the results on different scales would have been relevant and informative. In fact, both of the above topological approaches are complementary, although they require the use of different quantitative tools. Such network analysis tools are combined in software packages (e.g. the Pajek program for the analysis and visualisation of large networks (Batagelj and Mrvar 2009; Nooy et al. 2005) used by Isaksen) which are sometimes designed for specific disciplines, like the UCINET program for social network analysis (Borgatti et al. 1999) used by Graham. Network analysis can be used at any conceivable scale. But archaeologists using network analysis should be aware of the possible diversity of quantitative approaches, the scale on which they work, their structural and interpretative implications, and the software available to execute them.

\section{Social network analysis?}

In his work on Roman networks, Graham (2006a; 2006b; 2009) purposefully adopts a social network analysis method. He states that "Individuals must make something of these 
interconnections, for the networks to work" (Graham 2009, 675; see also Graham 2006b, 49). In Graham's work discussed above such a sociological approach is understandable, as the Roman perception of space is examined. Another enlightening example of the use of a social network method for archaeological topics is Graham's (2006a; 2009) study of the individuals active in the Roman brick industry in central Italy. By combining information on brick producing centres, derived from an archaeometrical analysis of clay sources, with names of individuals appearing on brick stamps, a social network of people could be constructed and analysed. Graham identified a small-world pattern in this social network, where Domitia Lucilla, mother of Marcus Aurelius, occupied a structurally favourable position through which she was able to control the flow of information in the brick trade (Graham 2006a, 93-114; Graham 2009, 681).

As the above examples illustrate, a social network approach can provide an innovative view on old data, and allows archaeologists to study the relationships, of whatever nature, between individuals in the past directly. The danger exists, however, that the insistence on humanising networks will lead to the misconception that all archaeological network analysis is social network analysis. In fact, only when the interactions between people are analysed directly, can social network analysis with its specific quantitative tools and interpretations be applied. As will be illustrated through the case study below, it is much easier and equally informative to identify and analyse non-social relationships in archaeological datasets, like the relationships between pots with the same motifs for example. That most archaeological relationships have social implications is obvious, as archaeologists are concerned with studying past human behaviour through an archaeological record that is itself created by people. But archaeologists should not assume that the structure of such social implications is examined directly through any type of network analysis. Focusing exclusively on the social application of network analysis restricts its use for the archaeological discipline, and limits the potential diversity of future archaeological applications of network analysis. 


\section{Static or dynamic?}

By combining network analysis and agent-based modelling, Graham (2006b) touched upon the issue of evolving networks. Several authors have expressed the need to focus on dynamic networks, to understand how network structure emerges and evolves (Barabàsi 2005; Bentley and Shennan 2003). Through material remains, archaeologists are informed of processes that took place at a specific moment or period in time. These allow us to study the evolution of human behaviour through individual light flashes scattered over an otherwise dark archaeological time scale. But can network analysis be used to represent this evolution? Is it a fundamentally static or dynamic method?

When describing his network as static, Graham $(2006 \mathrm{~b}, 48)$ largely referred to his analytical method and the nature of his data source, which presents a static image of a selection of travel routes in the Roman empire. Structural properties of this static network were determined, and programmed agents were set loose on the travel routes with the sole objective to share a piece of information. The network itself could not be considered dynamic, however, as its structure did not evolve but merely served as a medium for human interactions. Graham performed a dynamic exploration of the structural implications of a static network.

There are a few examples of the examination of evolving archaeological networks, however. Knappett et al. (2008) devised a mathematical model for the description of maritime networks. The model is based on a fixed input determined by the physical location of known sites in the Southern Aegean and the locally available resources, while decisions to make or break relationships are motivated by the idea of like to seek out like, where large sites will seek connections with other large sites. The authors implement this idea of 'gravitational attraction' by weighing the costs and benefits of maintaining connections, acting like a balance of social forces. When run, the model produces continually evolving networks of interconnections with particular strengths between 
communities of a particular size. The resulting networks can subsequently be explored with a diverse range of network analysis tools. In their examination of the spread and persistence of cultural traits, Bentley and Shennan (2003) proposed a mathematical model to make analytical predictions for unbiased transmission in cultural evolution. This model, adapted from Adamic and Huberman (2000), produces scale-free networks as a result of stochastic network growth. The authors applied this model to a pottery dataset from a linear Bandkeramik settlement in the Merzbach valley (Germany), where individual motifs were represented by nodes and copies of those motifs by connections leading towards these nodes. The specific structure and evolution of a scale-free network, as described by Barabàsi and Albert (1999) and discussed above (Fig. 2), explains "why a few highly popular styles can be expected to emerge in the course of cultural evolution" (Bentley and Shennan 2003, 459). The models presented here provide interesting methods for exploring the structural implications of hypothetical evolving networks.

The archaeological examples of network analysis discussed in this article indicate that it can be used for exploring both static and dynamic networks. Good archaeological examples of both approaches are scarce though, and do not tap into the full potential of network analysis techniques. For example, other than mathematical models evolving phenomena can be studied through chronologically subsequent networks of archaeological data, as shall be illustrated in the case study below. In other disciplines, the study of diffusion (Nooy et al. 2005, 161-183; Rogers 1995; Valente 1995), genealogies (Nooy et al. 2005, 226-242) and even citation analysis (Garfield 1979; Nooy et al. 2005, 242-250), through networks implies a time dimension. Both static and dynamic network approaches are therefore potentially informative for the archaeological discipline.

\section{The problem}

Through the above examples we have tried to indicate how network theory and network analysis techniques have been used to answer archaeological questions. Although all of the authors come to 
interesting and innovative results, their use of network analysis is often restricted and sometimes uncritical. If we want to continue applying network analysis in the archaeological discipline, there are a number of issues to be addressed:

- The role of archaeological data in networks

- The diversity of network structures, their consequences and their interpretation

- The critical use of quantitative tools

- The influence of other disciplines, especially sociology

In what follows these issues will be explored through a case study of table ware distributions in the Roman East, with the aim of proposing some general guidelines for the future use of network analysis in the archaeological discipline.

\section{CASE STUDY: TABLE WARE DISTRIBUTIONS IN THE ROMAN EAST}

\section{A complex dataset}

The word "simple" is possibly the worst description of the information archaeologists rely on for reconstructing the past. This is largely because every aspect of the archaeological process depends on selection. To illustrate this statement the Inventory of Crafts and Trade in the Roman East (ICRATES) platform of Prof. Dr. Jeroen Poblome (Katholieke Universiteit Leuven) is discussed (Bes and Poblome 2006, Bes and Poblome 2008) ${ }^{1}$. The ICRATES project has been assembling a nearly exhaustive database (contents summarised in Table 1) of published table wares from the Roman East. At the moment over 25,000 individual table ware sherds datable between the second century $\mathrm{BC}$ and the seventh century $\mathrm{AD}$ are included. The ICRATES database is a creation, resulting from a variety of processes in the archaeological past and the recent academic past. The

1 http://www.arts.kuleuven.be/icrates/. 
physical features of vessels, for example, were determined by people in the past, by selecting a clay source, a production method and a desired shape, in a given socio-economic and socio-cultural context. But the ICRATES database is also an aggregation of data from sites all over the Eastern Mediterranean, excavated by different teams and described by different ceramologists or archaeologists, each possibly working within a strongly dissimilar academic framework. It can therefore be stated with some certainty that, due to processes of selection, "complexity" is preferable to "simplicity" as a description of archaeological datasets like the ICRATES database.

Making sense of a complex archaeological dataset is not an easy task. In order to understand a complex structure, one needs to understand what it is made up of, what its organising principles are, and how it evolves. A suitable approach would be to consider the complexity of an archaeological dataset as a result of the dynamic interactions between its individual parts, like a complex system (Batty 2005; Bentley and Maschner 2003; Bertalanffy 1968; Rescher 1998). As network analysis allows one to explore the structure of relationships between individual entities directly and without simplification, it is considered a promising technique for exploring complex archaeological datasets.

\section{Identifying networks}

"Trying to represent a complex system by models that have the conceptual rigidity required for convenient management and manipulation is like trying to wrap a ball with an inflexible board: we simply cannot achieve the necessary fit" (Rescher 1998, 16).

Although network analysis is a suitable approach for exploring parts of a complex dataset, the above statement stresses that this exploration will never capture the dataset's full complexity. This is because the archaeological data in a complex dataset can interact through a variety of different and interwoven relationships. Looking at the summarised contents of the ICRATES database (Table 1) 
already reveals a number of such relationships, like the nationalities of teams excavating in certain regions around the Eastern Mediterranean or the forms identified in certain types of deposits. Research aims will determine for the most part what networks are identified and explored in the data available. Although they are complex on their own, these networks will never cover the full complexity of an archaeological dataset. It therefore becomes crucial to define the nature of the components of a network, their relationships, the network itself, and the meaning of the procedure of every type of analysis from the outset. This is undoubtedly the most important stage in any network analysis, as one could calculate the structure of virtually any kind of relationship between data, but if we do not know what this structure and the resulting patterning represents any results will be meaningless.

In this article we are interested in exploring the potential of a network analysis approach for archaeological research, in light of the issues we identified in previous archaeological applications of network analysis. Some conditions can therefore be taken into account to facilitate the identification of those networks that are most relevant for the article's aim. Firstly, the role of archaeological data in creating and examining networks should be discussed. This forces us to construct networks representing specific relationships between archaeological data in all their complexity. Secondly, the possible diversity of archaeological applications and the techniques for analysing such networks should be explored. For this purpose the current case study will perform both an exploratory approach, by examining the relationships between archaeological data directly, and a confirmatory approach, aimed at testing an archaeological hypothesis. Thirdly, the interpretation of network analysis results should be discussed. Interpretations should explicitly aim at understanding archaeological structures, rather than sociological or geographical ones. In this sense we would like to address Batty's $(2005,152)$ statement that "what might appear to be a random distribution of activity in Euclidean space is often seen as being highly ordered on a 
network", and vice versa. As an example, the dynamics between physical and relational space will be explored in this case study.

Given these conditions, two types of networks were defined:

1. A relational network of co-presence, representing pottery distribution patterns.

2. A geographical network of distance, representing a hypothesis of shortest-distance trade routes.

\section{Method and analysis co-presence networks}

Archaeometric analyses, comparative studies of table ware fabrics and study of potter's stamps have resulted in the identification of producing regions, and sometimes individual production centres, for Eastern Sigillata A, B, C, D and Italian Sigillatas (Table 2). We can therefore establish action radii of production regions or centres, reflected in the presence of types of table ware in the Roman East. An approach centred on wares, however, will not succeed in identifying possible different circulation patterns within a ware's own distribution. We should, therefore, analyse the distributions of the individual forms of these wares, which will provide detailed patterns that can still be added up per ware. Moreover, this allows for evaluating how the academic conception of typologies influences our knowledge of distribution patterns.

The chronological scope of the ICRATES database allows for the evolution of patterns through time to be examined. It was decided to estimate the volume of recorded table ware sherds in circulation during 25-year periods, using a method devised by Fentress and Perkins (1988) and previously applied to the ICRATES data by Philip Bes (2007). The result for the periods BC are presented in Figure 3.

These pottery distribution patterns reflected in the ICRATES database can be captured in a single undirected network per period, with vertices representing sites or forms, the relationships between them indicating the presence of a form on a site, and the line values representing the number of 
sherds found on this site (Fig. 4). In this network, sites can only be connected with forms evidenced for that site, and forms can only be connected with sites on which they were found. This structure is called a two-mode network as it consists of two distinct sets of vertices (Nooy et al. 2005, 103). To facilitate analysis and interpretation, a two-mode network can be divided into two distinct onemode networks, as represented in Figures 5 and 6.

As explained above, establishing the meaning of every aspect of a network is crucial. So what do these networks actually tell us? The ties of a pottery form to all sites on which it is found represent, in their broadest sense, the distribution network of that pottery form as it is reflected in the dataset. The presence or absence of forms on the same sites in the same period (further referred to as copresence), are an indication of the similarity or dissimilarity of these forms' distribution networks. What network analysis allows us to do is to analyse the structure of these distribution networks per period which, in the words of Michael Batty (2005: 153), will help us understand the "processes that reach, maintain and evolve these structures".

The complexity of the ICRATES dataset becomes immediately apparent when inspecting the resulting dense networks (see Figures 4, 5 and 6), and a method is needed to make sense of these complex patterns. For this purpose, three quantitative techniques will be introduced and discussed. However, such a method is not necessarily restricted to quantitative tools. Indeed, one of the most enlightening ways of exploring complex networks is through visual inspection. Although these networks might look unordered at first glance, they are plotted according to a number of basic principles, the most important of which are that the distance between vertices expresses the strength or number of their ties, and that vertices that are related are drawn closer together than vertices that are not related (Nooy et al. 2005, 14). With these principles in mind we can immediately identify vertices with similar characteristics, and vertices with a strong or weak position in the network's structure. As an example we could discuss a pattern that is reflected in all of the case study's 
networks: the existence of a dense core, with many connections in- and outside the core, and a periphery with mainly connections to the core. This structural dichotomy can be understood as a reflection of the size and diversity of the dataset, with table ware sherds of some forms being more attested than others. Also, thanks to these visualisation principles clusters of sites with a comparable assemblage of table wares can be more easily identified. This is especially true for the periphery where similarity is often based on the presence of just one or two sherds (e.g. Figure 5).

For the initial exploration of complex networks of co-presence and to serve as a guideline for further quantitative analysis, hierarchical clustering can be used. The 'corrected Euclidean distance' algorithm used in the network analysis software package Pajek was applied to compute dissimilarity between vertices, as unlike other methods included in Pajek this algorithm takes the value of lines in account (Batagelj et al. 1992; Batagelj and Mrvar 2009, 33-34; Nooy et al. 2005, 265-237). Next, the hierarchical clustering technique groups vertices that are most similar together in clusters. The 'average' clustering method was applied, as it is widely used for archaeological data (Baxter 1994; Shennan 1997, 239-240) and was most suitable for expressing the heterogeneous nature of this case study's dataset. Results of hierarchical clustering are visualised in a dendrogram (e.g. Figure 7). However, the unchallenged results of hierarchical clustering should not be considered as being of archaeological significance (Read 1989, 46; Shennan 1997, 255). The results can be used to identify apparent clusters of sites or forms, but the technique does not allow for an easy understanding of these structures. For example, five sites at the bottom of the dendrogram in Figure 7 are strongly dissimilar to all other sites. But this dissimilarity is a result of the cluster's connections to all or most of the other sites, which the dendrogram does not represent. As such, structures identified with hierarchical clustering should be explained through an exploration of their individual structural features.

Similarity of vertices is partly determined by the strength of their ties: the larger the number of co- 
present forms found on two sites, the stronger their tie and the more interdependent they are. To explore the strength of ties, the vertices can be classified according to their line values, introducing the concept of m-slices as a second quantitative tool (Nooy et al. 2005, 109; Scott 1991). M-slices consist of nested groups of vertices, as illustrated in Figure 8, and the 'm' stands for the line value of the group or 'slice'. In the co-presence network of forms, the forms that are part of a high m-slice are those that are present on many sites. The m-slices in the co-presence networks of sites (e.g. Figure 5), are an indication of the diversity of forms evidenced on these sites. For this case study, m-slices will therefore be used to establish the width of a form's distribution network as it is reflected in the archaeological record, and the number of attested distribution networks a site is part of. In the co-presence networks the highest values of ' $\mathrm{m}$ ' and also the highest diversity of values, are always to be found in the dense core as these vertices and their interconnections are based on a larger volume of table ware sherds.

A second quantitative tool does not focus on the strength of individual ties but on the number of ties a vertex has. Similar to the previous approach, k-cores are nested and 'k' stands for the core's number. Unlike m-slices, however, k-cores represent groups of sites or forms with at least a certain number of relationships (Nooy et al. 2005, 70-71). In a co-presence network of forms (e.g. Figure 6), a high k-core consists of forms that are co-present with many other forms. For the co-presence network of sites, a high k-core indicates that a site has evidence of forms that are present on many other sites. K-cores could therefore be used as an indication of the similarity of the distribution networks of forms, and the width of the distribution networks a site is part of. Contrary to m-slices, the highest values are not restricted to the dense core, but combine sites or forms from the entire network. The k-core values therefore seem to reflect the academic knowledge and use of table ware typologies, by indicating which groups of forms were identified together, and which individual forms were often identified on sites. 
The m-slice and k-core techniques introduced above each explore a different structural aspect of the networks of co-presence. By combining the results of both, groups of sites or forms with high or low ' $\mathrm{k}$ ' and ' $\mathrm{m}$ ' values can be identified, i.e. vertices with strong and many connections or the inverse. This allows for the structure of parts of the ICRATES dataset and the dynamics between different wares' distribution patterns to be explored directly in considerable detail. Although some wares are better attested than others, it is possible to identify the distinct distribution networks as they are represented by the table ware data. Using these tools to compare such ware specific networks and look for sites and forms where they overlap or differ, enhances our understanding of the processes that led to the distribution of table wares in the Roman East.

An exploratory analysis of co-presence networks identified evolving general structures like table ware distribution networks, and smaller patterns like clusters of sites or forms. In addition, the position individual sites and forms occupy on these networks can be examined with network analytical tools.

\section{Method and analysis distance networks}

Archaeologists have often used ceramics in attempts to reconstruct trade routes along which goods and people were transported (e.g. Fulford 1989; Reynolds 1995). Although our understanding of the general direction of trade becomes more accurate, thanks to an increasingly detailed knowledge on table ware producing sites and regions, the exact itineraries, however, are still largely unknown. This is mainly caused by an absence of evidence on what happened between the production and deposition of individual vessels. During its life cycle Roman pottery was subject to a wide variety of processes, which all contributed to the shaping of the archaeological record (Bonifay 2004; Peacock 1982; Peña 2007). The choice for a specific route could have been influenced by numerous factors, ranging from topography and sailing conditions, to the socio-political environment and even individual motivations (Horden and Purcell 2000, 124-135). Therefore, if we are to understand 
the processes that led to the attested table ware distributions, we should examine how each of the influencing factors is reflected in the archaeological record. For this case study, the influence of one single factor will be tested: distance. We state that Roman table ware vessels were transported during every part of their life cycle over trade routes chosen to minimise travel distance. If this hypothesis is true, then it should be reflected in our complex dataset.

Such an approach does not aim at creating a list of weighted factors that influenced the selection of trade routes in an attempt to identify the physical course of such routes. It merely explores to what extent the archaeological data itself can inform us of the continually evolving actions that led to its distribution and deposition. For this purpose, distance-based networks will be constructed and subsequently compared with the networks of co-presence introduced above.

This second network type should represent the geographical relationships between sites based on proximity, rather than relationships that are inherent to the ceramic data. Such a network can be created using a spatial clustering technique based on the relative neighbourhood concept. Contrary to more traditional clustering techniques that measure the absolute distance between two points (e.g. nearest neighbour analysis, Hodder and Orton 1976), the relative neighbourhood concept considers a region around pairs of points for creating relationships. The archaeological application of this concept has been discussed by Jiménez and Chapman (2002), stressing its use for revealing clusters at different resolutions (Toussaint 1980; Urquhart 1982; Kirkpatrick and Radke 1985). The latter can be achieved through the addition of a parameter Beta, creating a graph referred to as a Betaskeleton (Kirkpatrick and Radke 1985). Beta represents the size of the region of influence for each pair of points: if the region is small, more relationships will be drawn between the points; if the region is large, the network will start to fall apart in sub-networks. The result for different values of Beta is illustrated in Figure 9.

Assuming that vessels could have been transported from any site to any other site, networks per 
period right before they fall apart in sub-networks $($ Beta $=2)$ were created using this technique (e.g. Figure 10). Next, the transportation from centre of production to centre of deposition following the shortest path was simulated for every single sherd recorded in the database. This resulted in a distinct directed network per ware (e.g. Figure 11), reflecting the absolute volume of pottery transportation between any two sites. In addition, a combined network was created by adding up the values of the networks per ware, reflecting the complete distribution of table wares for each 25-year period over the shortest paths.

These networks representing the hypothesis of shortest distance transportation of the table ware sherds in the ICRATES database, can subsequently be examined with network analytical tools. The concept of m-slices was already discussed above, but its use and meaning alter significantly when applied to the hypothetical networks of distance. These networks are directed, and as a consequence, m-slices can represent arcs arriving at a vertex (input), departing from a vertex (output) or both (all). In this case the 'input' method can be considered most informative as it reflects the ceramic data attested at specific sites. Input m-slices represent the attested volume of pottery being transported to sites, and are an indication of the hypothetical overall activity in table ware transport over a specific trade route.

As these networks represent the transportation of goods over hypothetical trade routes between sites, one may wish to understand how easily they can be distributed, and what sites are more easily reachable than others. Closeness centrality is defined as "... the number of other vertices divided by the sum of all distances between the vertex and all others" (Nooy et al. 2005, 127; Sabidussi 1966). Again, as these networks are directed, a distinction should be made between 'input', 'output' and 'all' closeness centrality. Results of the 'output' closeness centrality for the networks of distance represent the relative ease with which a site's pottery can be transported to all other sites. 'All' closeness centrality, on the other hand, combines the input and output of vessels, and therefore 
reflects how easy a site can be reached from all other sites, and vice versa. A second centrality measure focuses on the idea that a vertex is more central if it is more important as an intermediary in the network. The betweenness centrality of a vertex is defined as the proportion of all shortest paths between pairs of other vertices that include this vertex (Nooy et al. 2005, 131). If the flow of goods between sites can be severely disrupted by the removal of one site, then this site is a crucial go-between to the transmission of goods in the network. Betweenness centrality can therefore be used to measure the hypothetical influence and control individual sites exercise in the transportation of table wares (e.g. Figure 11).

Contrary to centrality methods, the degree measure only takes a site and its direct neighbours into account. In a directed network, the outdegree of a vertex is the number of arcs it sends (Nooy et al. 2005 , 64). Defining the outdegree for every vertex allows one to identify all junctions in the hypothetical trade routes, and distinguish between the number of coinciding trade routes (e.g. Figure 11).

A final quantitative tool to be introduced is the concept of a domain. When goods are transported from site A to both sites B and C, the latter and all subsequent sites are dependent on the first for their provision of goods. The number of sites connected to site A serve as an indication for its domain of influence (Nooy et al. 2005, 193). A site's domain therefore represents the number of sites for which table wares are evidenced that were transported through this site. The output domain aids an understanding and comparison of sites where routes diverge, i.e. sites with an outdegree of more than one.

Major distribution routes and important centres in the transportation of individual wares were identified in hypothetical networks of distance. One could argue that the methods described here explore parts of the beta-skeleton selected for these networks rather than the ceramic data themselves, while only the m-slices take the volume of transported table ware sherds into account. 
Both aspects are equally important: one for examining the structure of the shortest paths, the other for identifying the most evidenced general directions of table ware distribution. A balanced exploration of the networks should therefore explain structural aspects in light of transported volumes and vice versa. All of the analytical tools introduced here will serve in exploring these hypothetical networks, but only a comparison with the networks of co-presence will allow for an evaluation of the hypothesis these represent.

\section{Interpretation: from structure to processes}

In the methodological sections above, a diverse arsenal of analytical weaponry for exploring archaeological networks was introduced. All of these quantitative tools examine distinct structural aspects, and produce different outputs and numerical results. Listing these detailed outputs and discussing the results with relevance to the plotted wares as well as the Roman socio-economic context is not within the scope of this article, however. But it should be clear that a variety of approaches exist for exploring archaeological networks, and that these provide different types of complementary information. In order to compare different networks, to test a hypothesis expressed as a network for example, these diverse results should be confronted critically to reach a meaningful interpretation. At this stage, the need expressed above to define from the outset every aspect of the networks and the analytical tools used becomes even more relevant. Methods should be selected that provide comparable results and examine similar structural aspects of networks, or a combination of tools might allow for individual patterns in networks to be validated or discarded. Although some of the methodological tools used in this case study are the same for both network types (like the m-slice method), they represent completely different aspects of the data and do not allow for a quantitative assessment. Therefore, the focus must be on comparing the most obvious patterns in both network types.

A comparison of the network types indicates that a short distance between sites and the proximity to 
the producing centres can be considered an influential factor that can serve to explain some patterns evidenced in the ICRATES dataset, such as the focus of Eastern Sigillata A distribution on Levantine sites and these sites' strong similarities in overall table ware distribution patterns. Other sites and wares for which distance was not a valid explanation could be identified as well, notably Alexandria, most of the Aegean and the connection with the Western Mediterranean.

When one considers distance to have been the only factor influencing decisions made in the distribution of table wares, some of the patterns do not seem to make much sense, confirming that pottery exchange mechanisms functioned as a dynamic system, with many small-scale actions leading to the general patterns we see in the archaeological record. One of the key issues for understanding these mechanisms is the relationship between east and west, which is evidenced in Italian Sigillata pottery being transported from Italy throughout the eastern Mediterranean. The presence of this ware in sites like Corinth, Knossos and Alexandria, for example, cannot be understood without considering their political situations and physical positions. The results of a networks approach should therefore be interpreted in a wider archaeological and historical framework (Poblome et al. 2004).

\section{DISCUSSION: TOWARDS ARCHAEOLOGICAL NETWORK ANALYSIS}

Although the context of this paper is too limited to provide an in depth analysis and interpretation of the table ware distributions, it clearly illustrated that network analysis is not a fixed method with a clearly defined set of analytical tools, and that this inherent flexibility allows for diverse applications of network analysis in the archaeological discipline. As was stated at the start of this article, however, this diversity has not yet found its way into the archaeological discipline. So how should this situation be overcome? The need exists to take a first step towards a specifically archaeological network analysis. 
As was illustrated in the case study, archaeological data can be represented as a network and the relationships between archaeological data can be examined directly. However, in complex archaeological datasets a wide variety of relationships can be identified. Therefore, the need was expressed to define every component of a network from the outset, as any conclusions drawn from an analysis of networks should be completely interpreted in light of these definitions. Moreover, analysing networks built from archaeological data, which are necessarily fragmentary samples of an unknown whole, will only provide direct information on the structure of these fragmentary archaeological sources themselves: the general structure of the data, small-scale patterns, and structural features of individual nodes in the network can be identified. Further interpretation of this patterning is largely outside the scope of network analysis techniques, although the structural consequences of identified patterns could help understand specific processes that led to the creation of the archaeological data examined. Network analysis can therefore be used to explore how archaeological data interacts. However, network analysis is not restricted to an exploratory purpose in archaeological applications. The case study revealed a second type of archaeological network that illustrates the method's use in a confirmatory approach. An archaeological hypothesis can be represented and tested as a network. Again, the diversity of possible hypotheses to be tested as a network is endless, ranging from geographical structure like in the case study, to social, temporal or material relationships. At any rate, archaeological data should occupy a central role in any archaeological network analysis. If networks are not completely created from archaeological information, then they should be validated by it.

Network analysis does not necessarily require a quantitative approach, as was illustrated by Sindbæk's (2007) work. Thinking about the past explicitly in terms of the interaction between material remains, people or places is highly informative. A special issue of the Mediterranean Historical Review (2007, number 22) edited by Malkin et al. (2007) is entirely devoted to such a 
qualitative use of a network paradigm for the historical discipline. However, a qualitative approach does not justify the uncritical use of network terminology, nor should it ignore the structural consequences of network patterns. For example, if one node in a network is considered to occupy a favourable position, this implies other nodes occupied a less favourable or even bad position. Both the identification of favourable and unfavourable positions should be grounded in archaeological data or reasoning. But more importantly, the interactions between these nodes will determine how the network evolves, which should be acknowledged and discussed when assigning a certain structure to the research topic in question.

In this article a large number of quantitative techniques for examining structural features of nodes and networks as a whole were introduced. The available archaeological data will to a large extent determine what techniques can be applied and how they need to be interpreted. However, as most examples of network analysis and all of the available software and manuals (e.g. Batagelj and Mrvar 2009; Borgatti 2002; Borgatti et al. 1999; Nooy et al. 2005) are dominated by perspectives from other disciplines, there is a real danger that these will affect the interpretation of archaeologically attested structure. To some extent this is already present in the first generation of archaeological applications of network analysis. In many of these works, networks are considered a medium for social interaction (Graham 2006a; 2006b; 2009; Isaksen 2008; Knappett et al. 2008; Sindbæk 2007), an idea central to social network analysis (Freeman 2004; Hanneman \& Riddle 2005) from which it was undoubtedly adopted in the archaeological discipline (see Figure 1). Although in some of the above cases networks explicitly represent media for human interaction, the archaeological network types discussed in the case study clearly indicate that this is not a prerequisite for all archaeological networks. Network analysis methods, quantitative tools and interpretative assumptions from other disciplines, especially sociology, should not be adopted unchallenged into the archaeological discipline, given the fundamentally different nature of their 
sources. Instead, an archaeological network analysis should be rooted in relational thinking which forms the core of network theory (Barabàsi 2002; Batty 2005), which all applications of network analysis have in common, and quantitative tools used in archaeological network analysis should be based on graph theory (Barnes and Harary 1983), physics (Albert and Barabàsi 2002) and, most importantly, archaeological reasoning.

\section{CONCLUSION}

A discussion of the current archaeological use of network analysis revealed a number of issues, largely resulting from an absence of archaeological network analysis examples and an incomplete adoption of network analysis methods from other disciplines. These issues and the potential of network analysis as a method for the archaeological discipline were explored through a case study of table ware distributions in the Roman East. A networks approach succeeded in identifying largeand small-scale patterns of relational, geographical or temporal significance in the case study's dataset. These patterns were visualized in structured graphs that encourage visual inspection, and a range of analytical tools was used to examine the different structural aspects these patterns consist of. It became clear that network analysis allows archaeologists to visualise and explore structures of relationships between archaeological data, or implied by archaeological hypotheses, directly.

Although there is a clear potential for network analysis as a method for archaeology, thus far it has been insufficiently explored and dominated by perspectives adopted from other disciplines. The need exists to work towards a specifically archaeological network analysis, drawing on the relational thinking of network theory and incorporating archaeological data critique and reasoning.

\section{Acknowledgements}

I would like to thank Prof. Simon Keay, Dr. Graeme Earl, Prof. Dr. Jeroen Poblome and Leif Isaksen for commenting on a draft of the article. The ICRATES platform is supported by project 
G.0788.09 of the Fund for Scientific Research, Flanders (FWO).

Archaeological Computing Research Group
School of Humanities
University of Southampton
Highfield
Southampton
SO17 1BF
$U K$
tb2v09@soton.ac.uk

\section{REFERENCES}

ADAMIC, A.L. and HUBERMAN, B.A. 2000: The nature of markets on the World Wide Web. Quarterly Journal of Electronic Commerce, 1, 5-12.

ALBERT, R. and BARABÀSI, A.-L. 2002: Statistical mechanics of complex networks. Reviews of Modern Physics, 74, 47-97.

ALBERT, R., JEONG, H. and BARABÀSI, A.-L. 1999: Internet: diameter of the World-Wide Web. Nature, 401, 130.

AMARAL, L.A.N., BULDYREV, S.V., HAVLIN, S., SALINGER, M.A. and STANLEY, H.E. 1998: Power law scaling for a system of interacting units with complex internal structure. Physical Review Letters, 80, 1385-1388.

AMARAL, L.A.N., SCALA, A., BARTHELEMY, M. and STANLEY, H.E. 2000: Classes of smallworld networks. Proceedings of the National Academy of Sciences of the United States of America, 97, 11149-11152.

BARABÀSI, A.-L. 2005: Network Theory-the Emergence of the Creative Enterprise. Science, 308, 639-641.

BARABÀSI, A.-L. 2002: Linked: the new science of networks (Cambridge, Massachusetts, Perseus).

BARABÀSI, A.-L. and ALBERT, R. 1999: Emergence of scaling in random networks. Science, 286, 509-512.

BARNES, J.A. and HARARY, F. 1983: Graph theory in network analysis. Social networks, 5, 235- 
BATAGELJ, V. 2005: Structure of networks I. Networks Workshop, NICTA, Sydney, http://vlado.fmf.uni-lj.si/pub/networks/doc/seminar/nicta03.pdf.

BATAGELJ, V., FERLIGOJ, A. and DOREIAN, P. 1992: Direct and indirect methods for structural equivalence. Social Networks, 14, 63-90.

BATAGELJ, V. and MRVAR, A. 2009: Pajek, program for analysis and visualization of large networks, reference manual version 1.25 (http://vlado.fmf.unilj.si/pub/networks/pajek/doc/pajekman.pdf).

BATTY, M. 2005: Network geography: relations, interactions, scaling and spatial processes in GIS. In Fisher, P. and Unwin, D. (eds.), Re-presenting GIS. (Chichester, Wiley), 149-169.

BAXTER, M.J. 1994: Exploratory multivariate analysis in archaeology (Edinburgh, Edinburgh University Press).

BENTLEY, R.A. and MASCHNER, H.D.G. 1999: Subtle nonlinearities in popular album charts. Advances in Complex Systems, 2, 197-209.

BENTLEY, R.A. and MASCHNER, H.D.G. 2000: A growing network of ideas. Fractals, 8, 227238.

BENTLEY, R.A. and MASCHNER, H.D.G. 2001: Stylistic evolution as a self-organized critical phenomenon. Journal of Archaeological Method and Theory, 8, 35-66.

BENTLEY, R.A. and MASCHNER, H.D.G. 2003: Complex systems and archaeology (Salt Lake City, University of Utah Press).

BENTLEY, R.A. and SHENNAN, S.J. 2003: Cultural transmission and stochastic network growth. American Antiquity, 68, 459-485.

BERG, I. 1999: The southern Aegean system. Journal of World-Systems Research, 5, 475-484.

BERKOWITZ, S.D. and WELLMAN, B. 1988: Social structures: a network approach (Cambridge, Cambridge University Press). 
BERTALANFFY, L.V. 1968: General system theory: foundations, development, applications (New York, Braziller).

BES, P. 2007: A geographical and chronological study of the distribution and consumption of table wares in the Roman East. Unpublished doctoral thesis (Leuven, K.U.Leuven).

BES, P. and POBLOME, J. 2006: A new look at old data: the ICRATES platform. In Malfitana, D., Poblome, J. and Lund, J. (eds.), Old pottery in a new century: innovating perspectives on Roman pottery studies. Catania: Monografie dell'Istituto per i Beni Archeologici e Monumentali, 22-24 April 2004 (Rome, Bretschneider), 141-165.

BES, P.M. and POBLOME, J. 2008: (Not) see the Wood for the Trees? 19,000+ Sherds of table wares and what we can do with them. In Biegert, S. (ed.), Rei Cretariae Romanae Fautores Acta 40. (Bonn), 505-514.

BONIFAY, M. 2004: Etudes sur la céramique romaine tardive d'Afrique. BAR International Series 1301 (Oxford, Archaeopress).

BORGATTI, S. 1999: Keyplayer version 1.44 (Nantick, Massachusetts, Analytic Technologies).

BORGATTI, S.P. 2002: Keyplayer v.1.1 (Nantick, Massachusetts, Analytic Technologies).

BORGATTI, S.P., EVERETT, M.G. and FREEMAN, L.C. 1996: UCINET Iv version 1.64 (Nantick, Massachusetts, Analytic Technologies).

BORGATTI, S., EVERETT, M. and FREEMAN, L. 1999: UCINET 6.0, Version 1.00 (Nantick, Massachusetts, Analytic Technologies).

BROODBANK, C. 2000: An island archaeology of the early Cyclades (Cambridge, Cambridge University Press).

BUCHANAN, M. 2002: Nexus: small worlds and the groundbreaking science of networks (New york).

BURDA, Z., JOHNSTON, D., JURKIEWICZ, J., KAMISKI, M., NOWAK, M.A., PAPP, G. and ZAHED, I. 2002: Wealth condensation in Pareto macroeconomies. Physical Review E, 65, 026102. 
CARRINGTON, P.J., SCOTT, J. and WASSERMAN, S. 2005: Models and methods in social network analysis (Cambridge ; New York, Cambridge University Press).

CHERRY, J.F. (1977) Investigating the political geography of an early state by multidimensional scaling of Linear B tablet data. In Bintliff, J. (Ed.) Mycenaean geography: proceedings of the Cambridge colloquium, September 1976, 76-82. British Association for Mycenaean Studies. Cambridge University Library.

CHORLEY, R. and HAGGETT, P. 1969: Network analysis in geography: an exploration in spatial structure (London, Arnold).

CILLIERS, P. 1998: Complexity and postmodernism: understanding complex systems (London, Routledge).

CLARK, E. 1992: Elite networks and heresy accusations: towards a social description of the Origenist controversy. Semeia, 56, 74-117.

DULING, D. 1999: The Jesus movement and social network analysis (Part I: the spatial network). Biblical Theology Bulletin, 29, 156-175.

ETTLINGER, E., KENRICK, P.M., ROTH-RUBI, K. and ZABEHLICKY-SCHFFENEGGER, S. 1990: Conspectus formarum Terrae Sigillatae Italico modo confectae (Bonn).

EVANS, T.S. 2004: Complex networks. Contemporary Physics, 45, 455-474.

EVANS, T., KNAPPETT, C. and RIVERS, R. 2009: Using statistical physics to understand relational space: a case study from Mediterranean Prehistory. In Lane, D., D.Pumain, Leeuw, S.v.d. and G.West (eds.), Complexity perspectives on innovation and social change.

FENTRESS, E. and PERKINS, P. 1988: Counting African Red Slip Ware. In Mastino, A. (ed.), L'Africa Romana: Atti del V Convegno di studio Sassari, 11-13 dicembre 1987. (Sassari), 205-214.

FREEMAN, L.C. 1977: A set of measures of centrality based on betweenness. Sociometry, 40, 3541.

FREEMAN, L. 2004: The development of social network analysis (Vancouver, Empirical Press).

FULFORD, M.G. 1989: To East and West: the Mediterranean trade of Cyrenaica and Tripolitania in 
antiquity. Libyan Studies, 20, 169-191.

GARFIELD, E. 1979: Citation indexing: its theory and application in science, technology, and humanities (New York, Wiley).

GINELLI, M., FASS, G. and TURTLE., B. 1996: Six degrees of Kevin Bacon (New York, Plume).

GRAHAM, S. (2002) 'Ex Figlinis': the complex dynamics of the Roman brick industry in the Tiber valley during the 1 st to 3rd Centuries $\mathrm{AD}$, PhD thesis. School of Human and Environmental Sciences, University of Reading.

GRAHAM, S. 2005: Agent-based modelling, archaeology and social organisation: the robustness of Rome. The Archaeological Computing Newsletter, 63, 1-6.

GRAHAM, S. 2006a: EX FIGLINIS, the network dynamics of the Tiber valley brick industry in the hinterland of Rome, British Archaeological Reports International Series 1486 (Oxford, Archaeopress).

GRAHAM, S. 2006b: Networks, agent-based models and the Antonine itineraries: implications for Roman archaeology. Journal of Mediterranean Archaeology, 19, 45-64.

GRAHAM, S. 2006c: Who's in charge? Studying social networks in the Roman brick industry in central Italy. In Mattusch, C. and Donohue, A. (eds.), Acta of the XVIth International Congress of Classical Archaeology. (Oxford, David Brown Book Company), 359-362.

GRAHAM, S. 2009: The space between: the geography of social networks in the Tiber valley. In Coarelli, F. and Patterson, H. (eds.), Mercator Placidissimus: the Tiber valley in Antiquity. New research in the upper and middle river valley. (Proceedings of the Conference held at the British School at Rome, 27-28 Feb. 2004). (Rome, British School at Rome - Edizioni QVASAR.).

GRANOVETTER, M.S. 1973: The strength of weak ties. American Journal of Sociology, 78, 13601380 .

HAGE, P. and HARARY, F. 1991: Exchange in Oceania: a graph theoretic analysis (Oxford, Clarendon Press).

HAGE, P. and HARARY., F. 1996: Island networks: communication, kinship and classification structures in Oceania (Cambridge, Cambridge University Press). 
HANNEMAN, R.A. and RIDDLE, M. 2005: Introduction to social network methods (Riverside: University of California, Riverside).

HARARY, F. 1969: Graph theory (Reading, Massachusetts; London, Addison-Wesley).

HARARY, F. and NORMAN, R.Z. 1953: Graph theory as a mathematical model in social science (Ann Arbor, University of Michigan, Institute for Social Research).

HAYES, J.W. (1985) Sigillate orientale. Enciclopedia dell'arte antica. classica e orientale. Atlante della forme ceramiche II: ceramica fine romana nel bacino mediterraneo (tardo ellenismo e primo imperio). (Rome).

HODDER, I. and ORTON, C. 1976: Spatial analysis in archaeology (Cambridge, Cambridge University Press).

HOHENBERG, P.M. and LEES, L.H. 1996: The making of urban europe 1000-1994 (Cambridge Massachusetts, Harvard University Press).

HORDEN, P. and PURCELL, N. 2000: The corrupting sea : a study of Mediterranean history (Oxford, Blackwell).

HUBERMAN, B.A. and ADAMIC, A.L. 1999: Growth dynamics of the World Wide Web. Nature, 401, 131-132.

IRWIN, G. 1983: Chieftainship, kula and trade in Massim prehistory. In Leach, J.W. and Leach, E. (eds.), The Kula: new perspectives on Massim exchange. (Cambridge, Cambridge University Press), 29-72.

ISAKSEN, L. 2008: The application of network analysis to ancient transport geography: A case study of Roman Baetica. Digital Medievalist, 4, http://www.digitalmedievalist.org/journal/4/isaksen/.

JIMÉNEZ, D. and CHAPMAN, D. 2002: An application of proximity graphs in archaeological spatial analysis. In Wheatley, D., Earl, G. and Poppy, S. (eds.), Contemporary themes in archaeological computing, University of Southampton department of archaeology monograph 3. (Oxford, Oxbow Books) 90-99. 
KENDALL, D.G. 1971: Maps from marriages: an application of non-metric multidimensional scaling to parish register data. In Hodson, F.R., Kendall, D.G. and Tautu, P. (eds.), Mathematics in the archaeological and historical sciences. (Edinburgh, Edinburgh University Press), 303-318.

KENDALL, D.G. 1977: Computer techniques and the archival map reconstruction of Mycenaean Messenia. In Bintliff, J. (ed.), Mycenaean geography: proceedings of the Cambridge colloquium, September 1976, British Association for Mycenaean Studies. (Cambridge, Cambridge University Library), 83-87.

KIRKPATRICK, D.G. and RADKE, J.D. 1985: A framework for computational morphology. In Toussaint, G. (ed.), Computational geometry. (North-Holland, Elsevier Science Publishers), 217248.

KNAPPETT, C., EVANS, T. and RIVERS, R. 2008: Modelling maritime interaction in the Aegean Bronze Age. Antiquity, 82, 1009-1024.

KNAPPETT, C. and NIKOLAKOPOULOU., I. 2005: Exchange and affiliation networks in MBA southern Aegean: Crete, Akrotiri and Miletus. In Laffineur, R. and Greco, E. (eds.), Emporia: Aegeans in East and West Mediterranean. (Liège, University of Liège Ser. 25), 175-184.

KRAPIVSKY, P.L., REDNER, S. and LEYVRAZ, F. 2000: Connectivity of growing random networks. Physical Review Letters, 85, 4629-4632.

LATOUR, B. 2005: Reassembling the social: An introduction to actor-network theory (Oxford, Oxford University Press).

LEWIN, R. 1993: Complexity: life at the edge of chaos (London, Dent).

MA, J. 2003: Peer polity interaction in the Hellenistic age. Past and Present, 180, 9-39.

MALKIN, I. 2003: Networks and the emergence of Greek identity. Mediterranean paradigms and Classical Antiquity. Mediterranean Historical Review, 18, 56-74.

MALKIN, I., CONSTANTAKOPOULOU, C. and PANAGOPOULOU, K. 2007: Preface: networks in the Ancient Mediterranean. Mediterranean Historical Review, 22, 1-9.

MASSEY, D., ALLEN, J. and PILE, S. 1999: City worlds: understanding cities 1 (London, Routledge). 
MCPHERSON, M., SMITH-LOVIN, L. and COOK., J.M. 2001: Birds of a feather: homophily in social networks. Annual Review of Sociology, 27, 415-444.

MEYER-SCHLICHTMANN, C. 1988: Die pergamenischen Sigillata aus der Stadtgrabung von Pergamon. Mitte 2. JH v. Chr. - Mitte 2. JH n. Chr. (Berlin/New York).

MILGRAM, S. 1967: The small world problem. Psychology Today, 2, 60-67.

MÜLLER, K. 2002: Ptolemaic settlements in space: settlement size and hierarchy in the Fayum. Archiv für Papyrus-forschung und verwandte Gebiete, 48, 107-125.

NEWMAN, M.E.J. 2001: The structure of scientific collaboration networks. Proceedings of the National Academy of Sciences of the United States of America, 98, 404-409.

NEWMAN, M.E.J. 2002: Assortative mixing in networks. Physical Review Letters, 89, 208701. DOI: 208710.201103/PhysRevLett.208789.208701.

NEWMAN, M.E.J. and PARK, J. 2003: Why social networks are different from other types of networks. Physical Review E, 68, 036122. DOI: 036110.031103/PhysRevE.036168.036122.

NOOY, W.D., MRVAR, A. and BATAGELJ, V. 2005: Exploratory social network analysis with Pajek (Cambridge ; New York, Cambridge University Press).

PASTOR-SATORRAS, R. and VESPIGNANI, A. 2001: Epidemic spreading in scale-free networks. Physical Review Letters, 86, 3200-3203.

PEACOCK, D.P.S. 1982: Pottery in the Roman world: an ethnoarchaeological approach (London, Longman).

PEÑA, T. 2007: Roman pottery in the archaeological record (Cambridge, Cambridge University Press).

PITTS, F.R. 1965: A graph theoretic approach to historical geography. The Professional Geographer, 17, 15-20.

POBLOME, J., TALLOEN, P., BRULET, R. and WAELKENS, M. 2004: Early Italian sigillata: 
the chronological framework and trade patterns. Babesch: bulletin antieke beschaving. Supplement 10 (Leuven, Peeters).

READ, D.W. 1989: Statistical methods and reasoning in archaeological research: a review of praxis and promise. Journal of Quantitative Anthropology, 1, 5-78.

REMUS, H. 1996: Voluntary association and networks: Aelius Aristides at the Asclepieion in Pergamum. In Kloppenborg, J. and Wilson, S. (eds.), Voluntary associations in the Graeco-Roman world. (London, Routledge), 146-175.

RESCHER, N. 1998: Complexity: a philosophical overview (New Brunswick, Transaction).

REYNOLDS, P. 1995: Trade in the Western Mediterranean, AD 400-700: the ceramic evidence (Oxford).

RIHLL, T.E. and WILSON, A.G. 1991: Modelling settlement structures in ancient Greece: new approaches to the polis. In Rich, J. and Hadrill, A.W. (eds.), City and country in the ancient world. (London), 59-96.

ROGERS, E.M. 1995: Diffusion of innovations, 4th edition (New York, The Free Press).

SABIDUSSI, G. 1966: The centrality index of a graph. Psychometrika, 31, 581-603.

SCOTT, J. 1991: Social network analysis: a handbook (London).

SCOTT, J. 2000: Social network analysis. A handbook. 2nd ed. (London, Thousand Oaks, California and New Delhi, Sage Publications).

SHENNAN, S. 1997: Quantifying archaeology. 2nd edition (Edinburgh, Edinburgh University Press).

SINDBÆK, S.M. 2007: Networks and nodal points: the emergence of towns in early Viking Age Scandinavia. Antiquity, 81, 119-132.

TERRELL, J. 1977: Human biogeography in the Solomon Islands (Chicago, Field Museum of Natural History). 
TOUSSAINT, G.T. 1980: The relative neighborhood graph of a finite planar set. Pattern Recognition, 12, 261-268.

URQUHART, R. 1982: Graph theoretical clustering based on limited neighborhood sets. Pattern Recognition, 15, 173-187.

VALENTE, T.W. 1995: Network models of the diffusion of innovations (Creskill, NJ, Hampton Press).

WASSERMAN, S. and FAUST, K. 1994: Social network analysis: methods and applications (Cambridge, Cambridge University Press).

WATTS, D.J. 1999: Small worlds. The dynamics of network between order and randomness (Princeton, Princeton University Press).

WATTS, D.J. 2003: Six degrees: The science of a connected age (London, Vintage).

WATTS, D. and STROGATZ, S. 1998: Collective dynamics of 'small-world' networks. Nature, 393, 440-442. 


\section{CAPTIONS OF ILLUSTRATIONS}

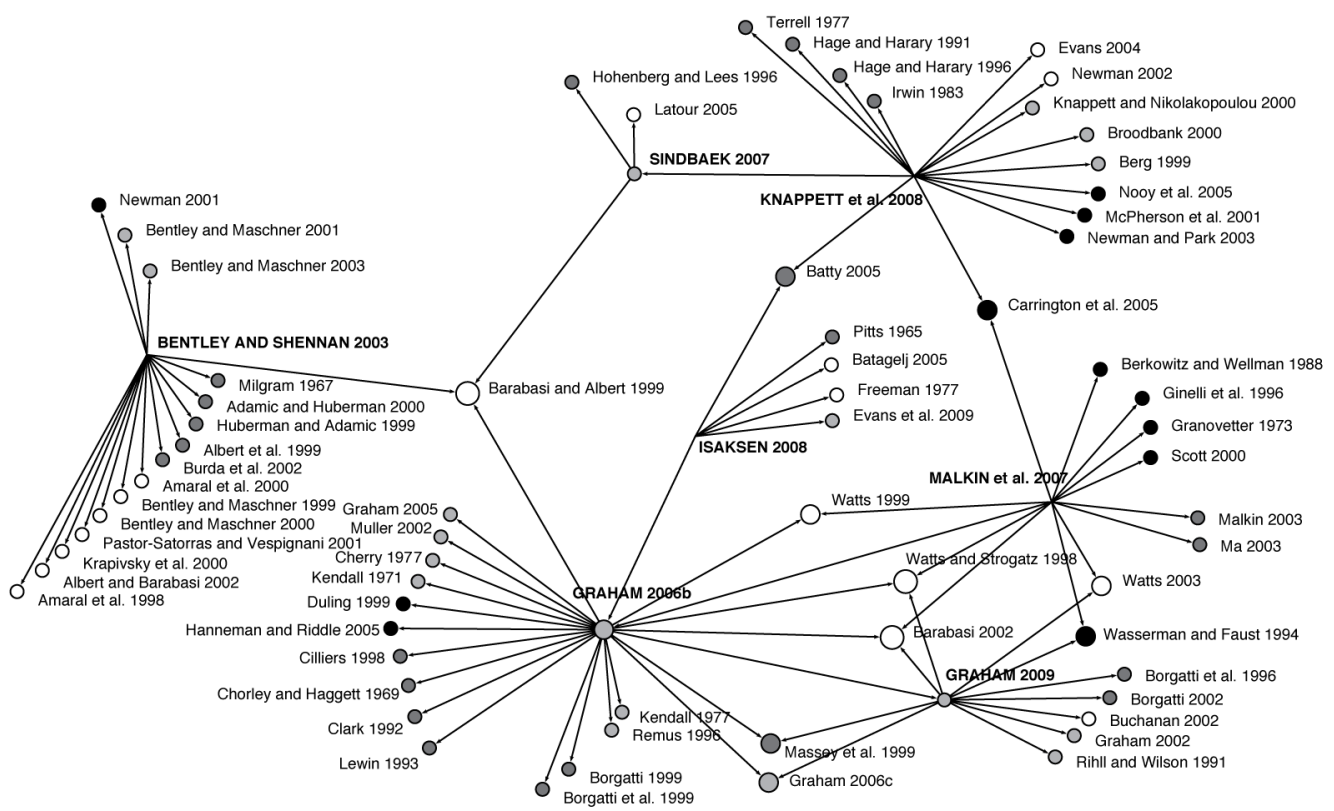

Figure 1

Citation network of archaeological applications of network analysis (in bold). Nodes represent publications on network analysis, arcs (directional relationships) represent a citation, the size of nodes indicates the number of direct citations a node receives from within this network, the colour of nodes represents the general academic field a publication belongs to (black $=$ sociology; white $=$ mathematics; light grey $=$ archaeology; dark grey $=$ other $)$.
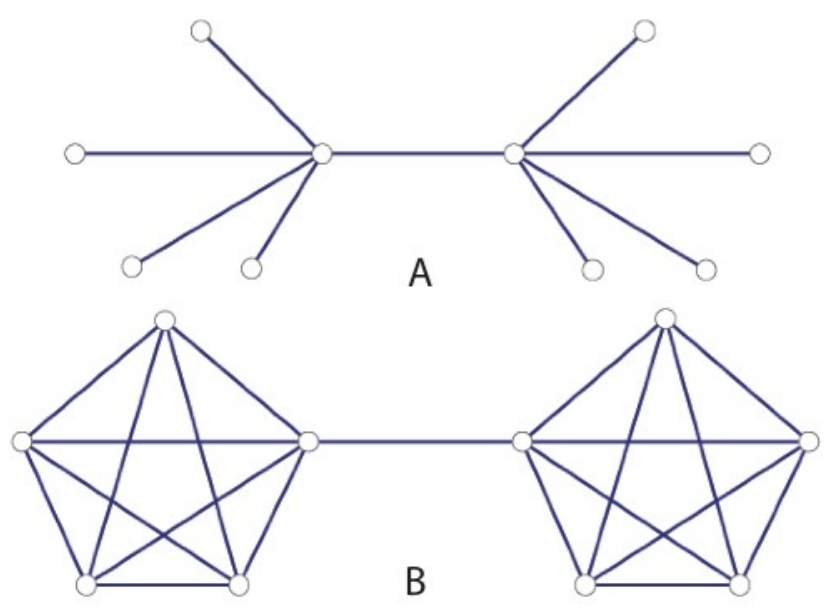
Figure 2

Schematic example of a scale-free network (A) and a small-world network (B).

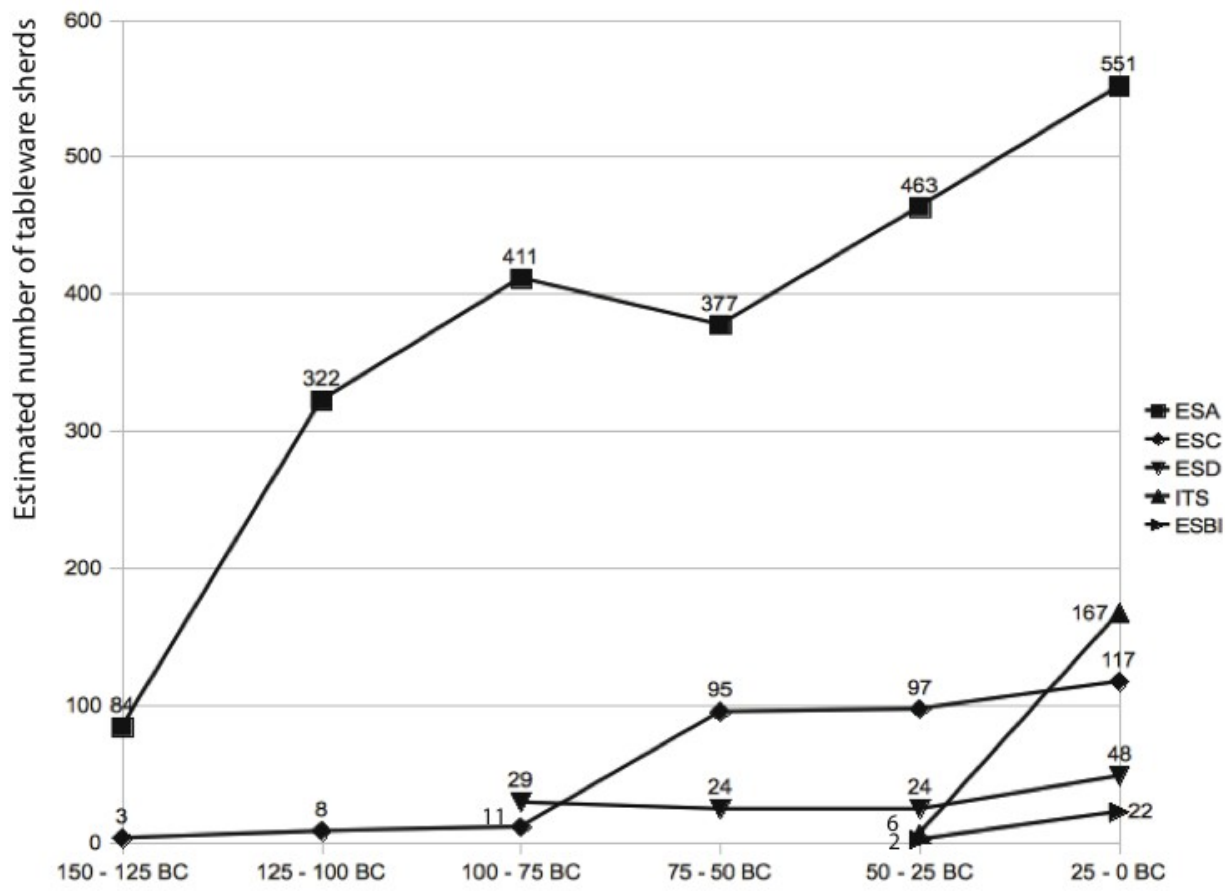

Figure 3

Evolution of the estimated number of table ware sherds included in the ICRATES database per ware $(150-0 \mathrm{BC})$. 


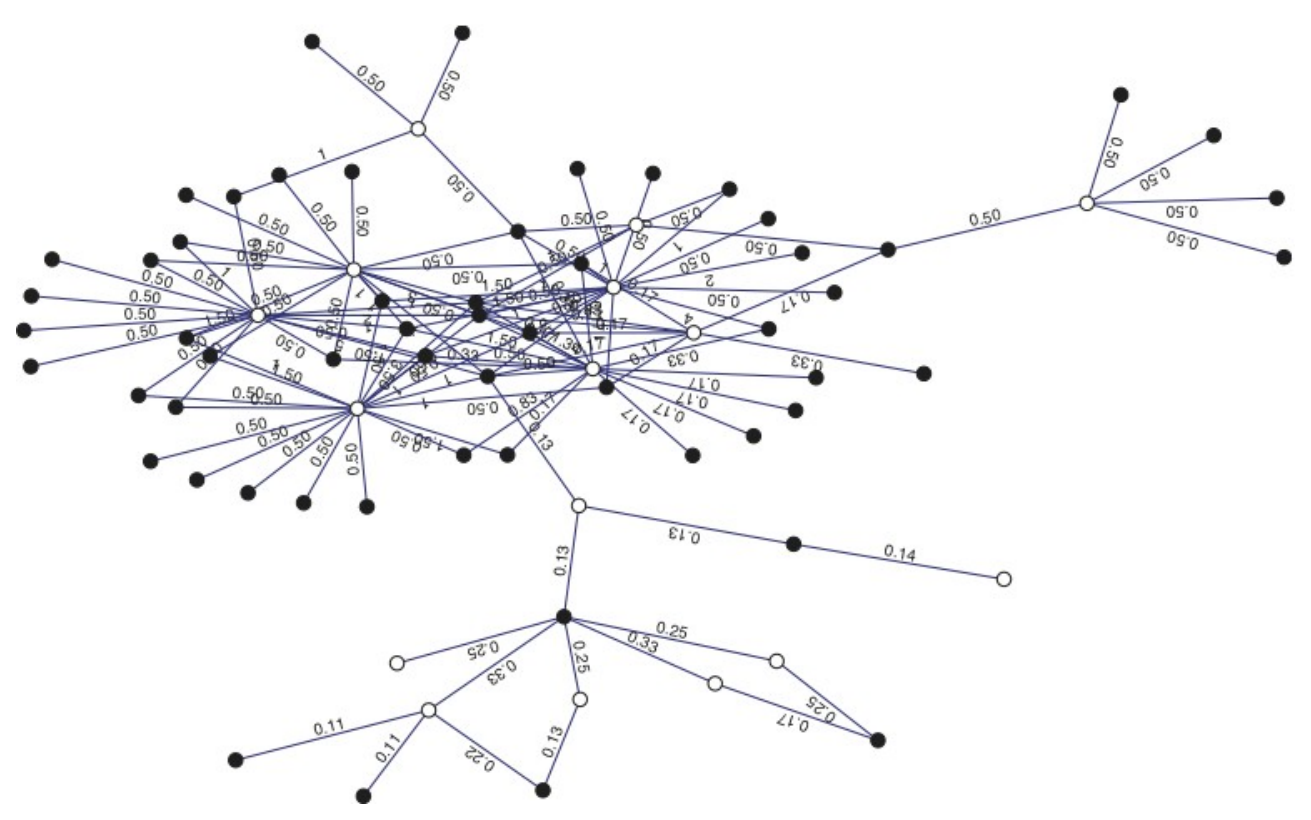

Figure 4

Two-mode network of the period 150-125 BC, representing sites (black) connected to pottery forms (white) which are present at the site. The value indicates the estimated number of sherds of a form that have been found. 


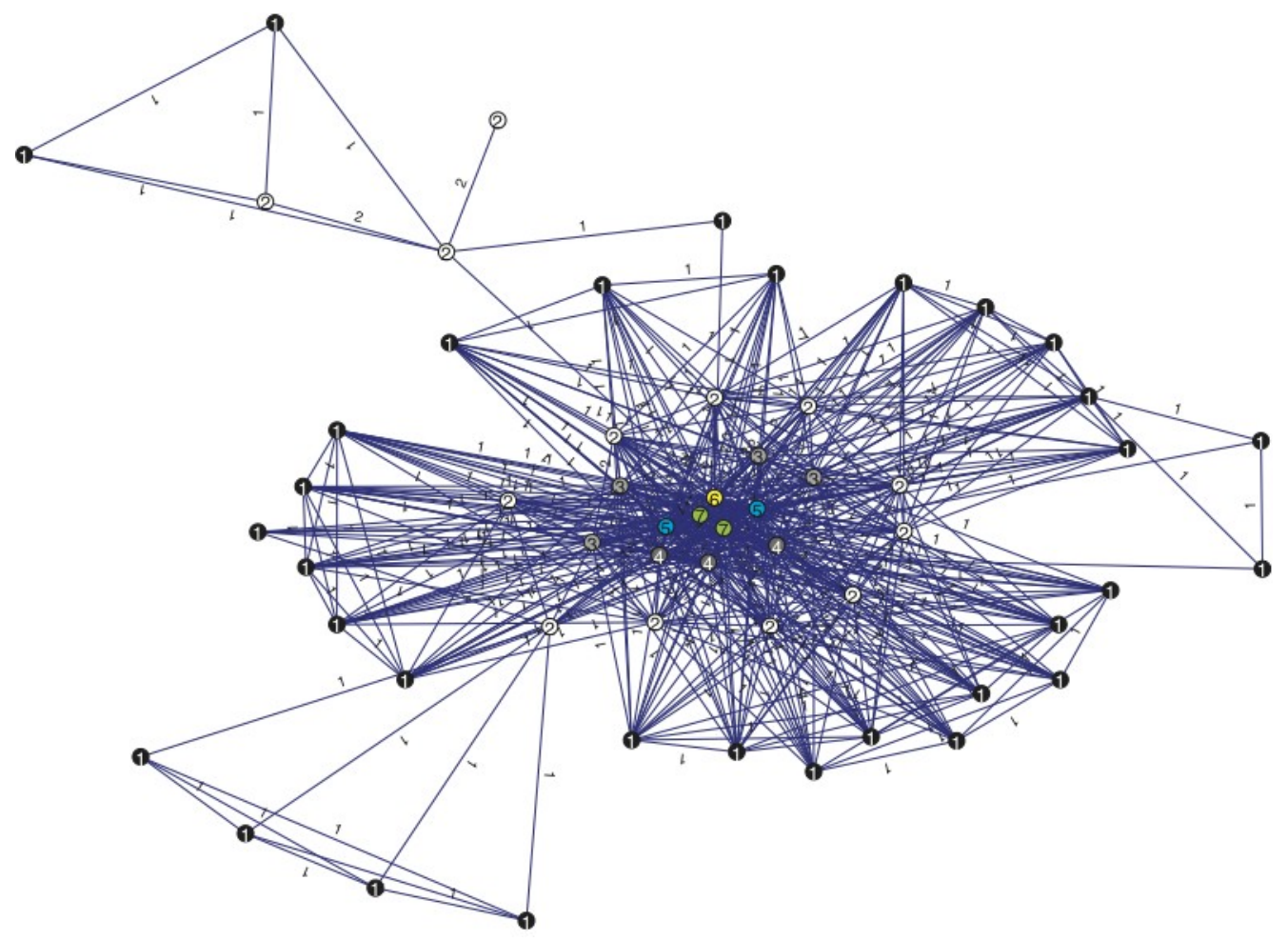

Figure 5

One-mode network of the period 150-125 BC, representing sites connected to sites which have evidence of the same pottery forms (co-presence). The line value indicates the number of pottery forms that are co-present. The colour and number of vertices indicate the m-slice they belong to.

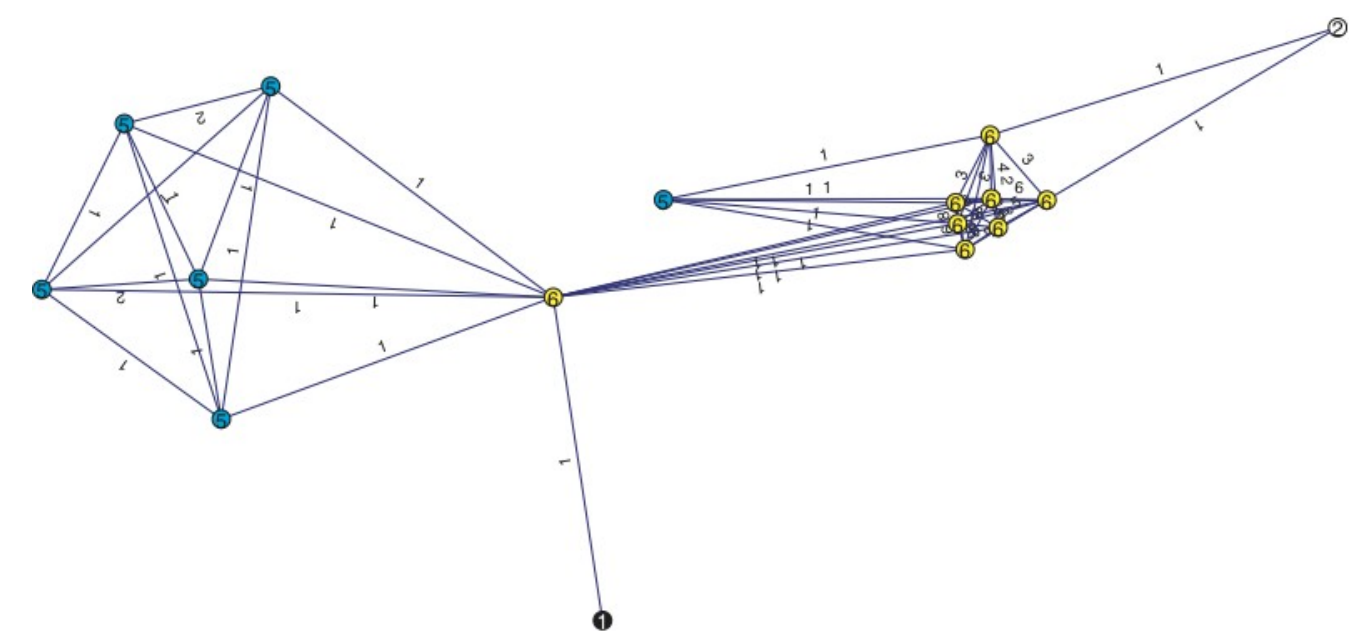


Figure 6

One-mode network of the period 150-125 BC, representing pottery forms connected to other pottery forms which have been found on the same site (co-presence). The value indicates the number of sites on which forms are co-present. The colour and number of vertices indicate the k-core they belong to. 


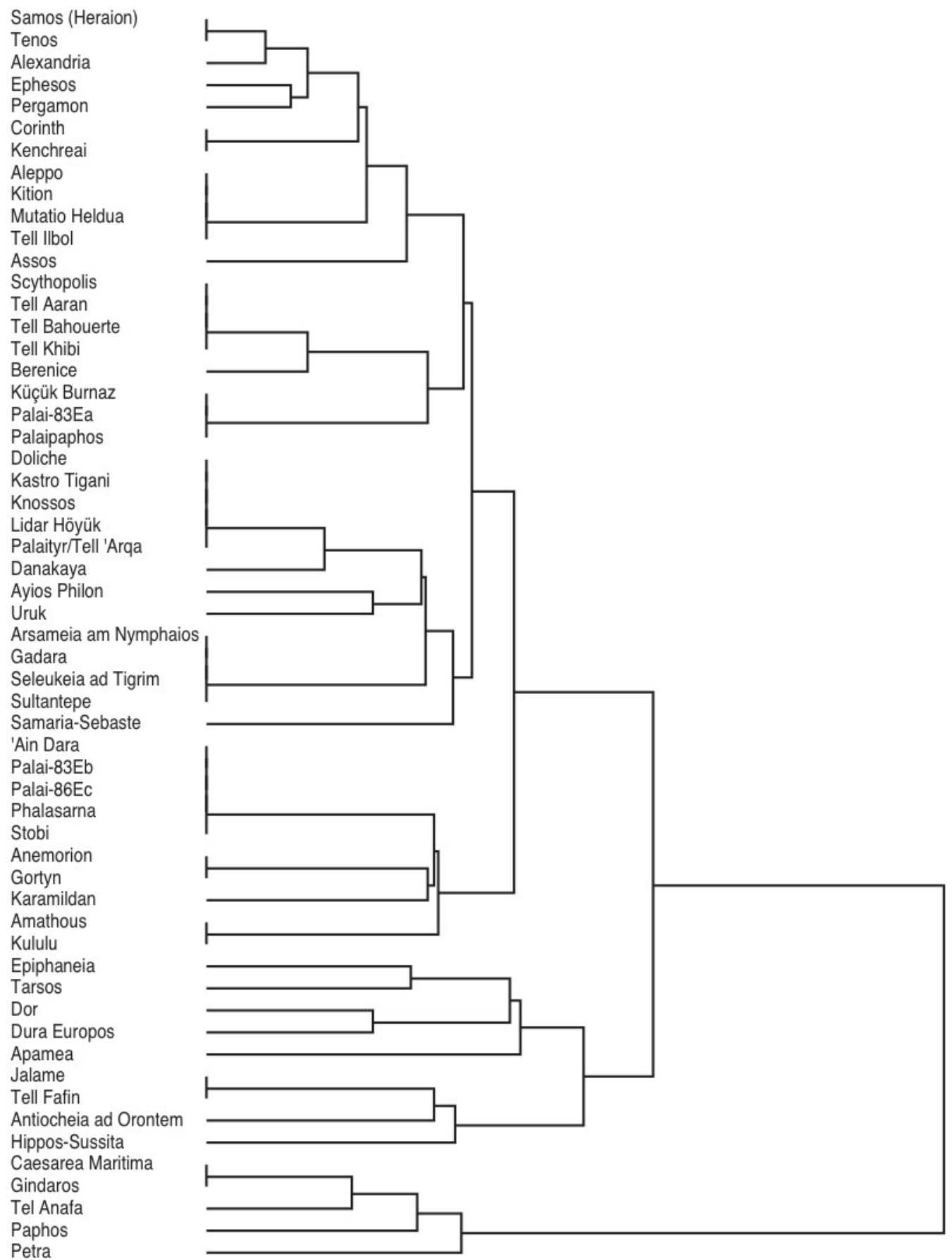

Figure 7

Example of a dendrogram for the sites network of the period 150-125 BC. It represents the increasing dissimilarity of the sites' table ware assemblages from left to right. 


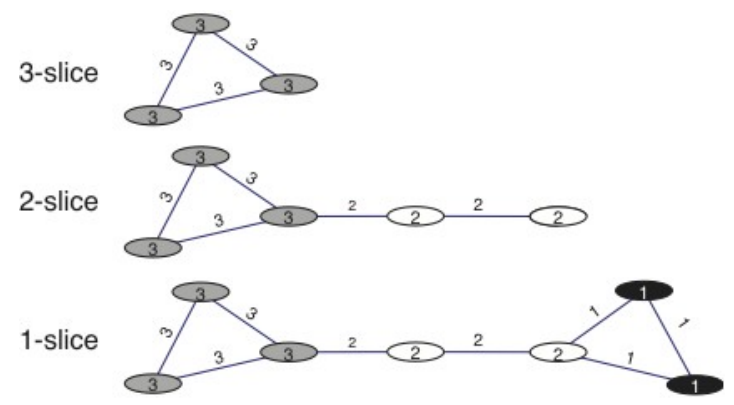

Figure 8

Schematic example illustrating the nesting of m-slices.

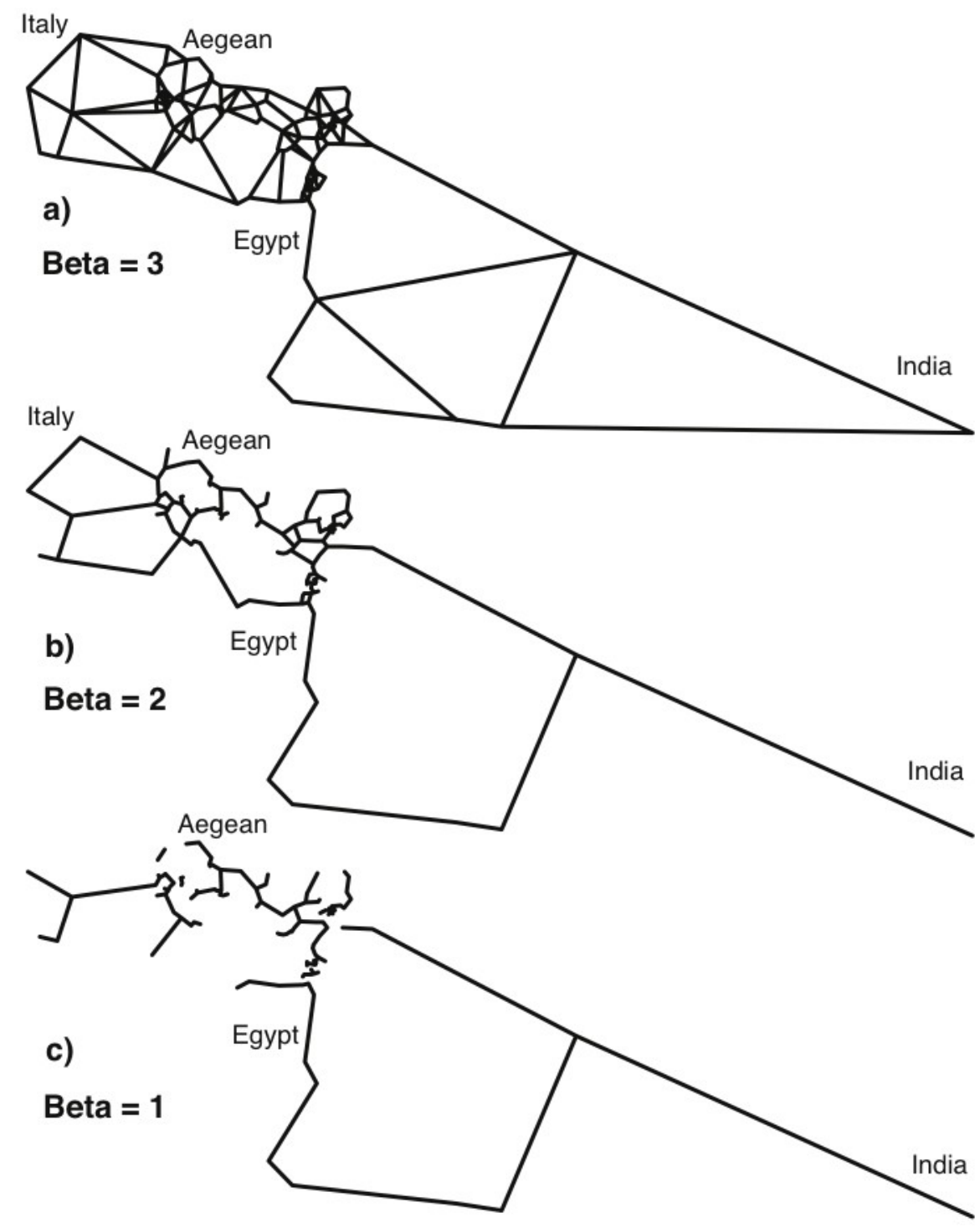


Figure 9

Beta-skeletons of sites for which table wares dated to the period 50-25 BC are attested, with beta values 3 (a), 2 (b) and 1 (c).

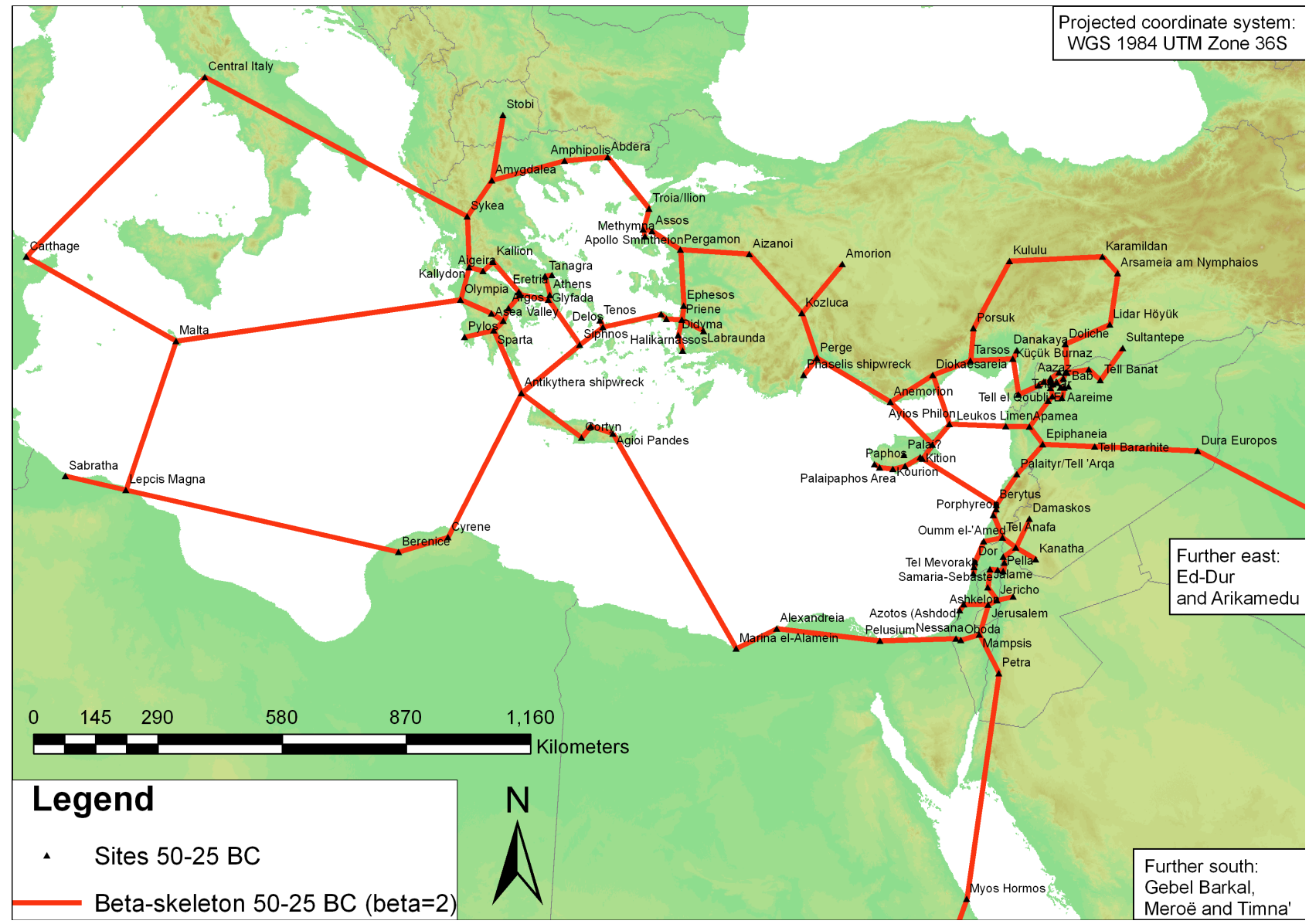

Figure 10

Beta-skeleton (beta=2) of sites for which table wares dated to the period 50-25 BC are attested. Source topography and boundaries: Demis WMS server (http://www2.demis.nl/wms/wms.asp? $\underline{\text { wms }=\text { WorldMapand }) .}$ 


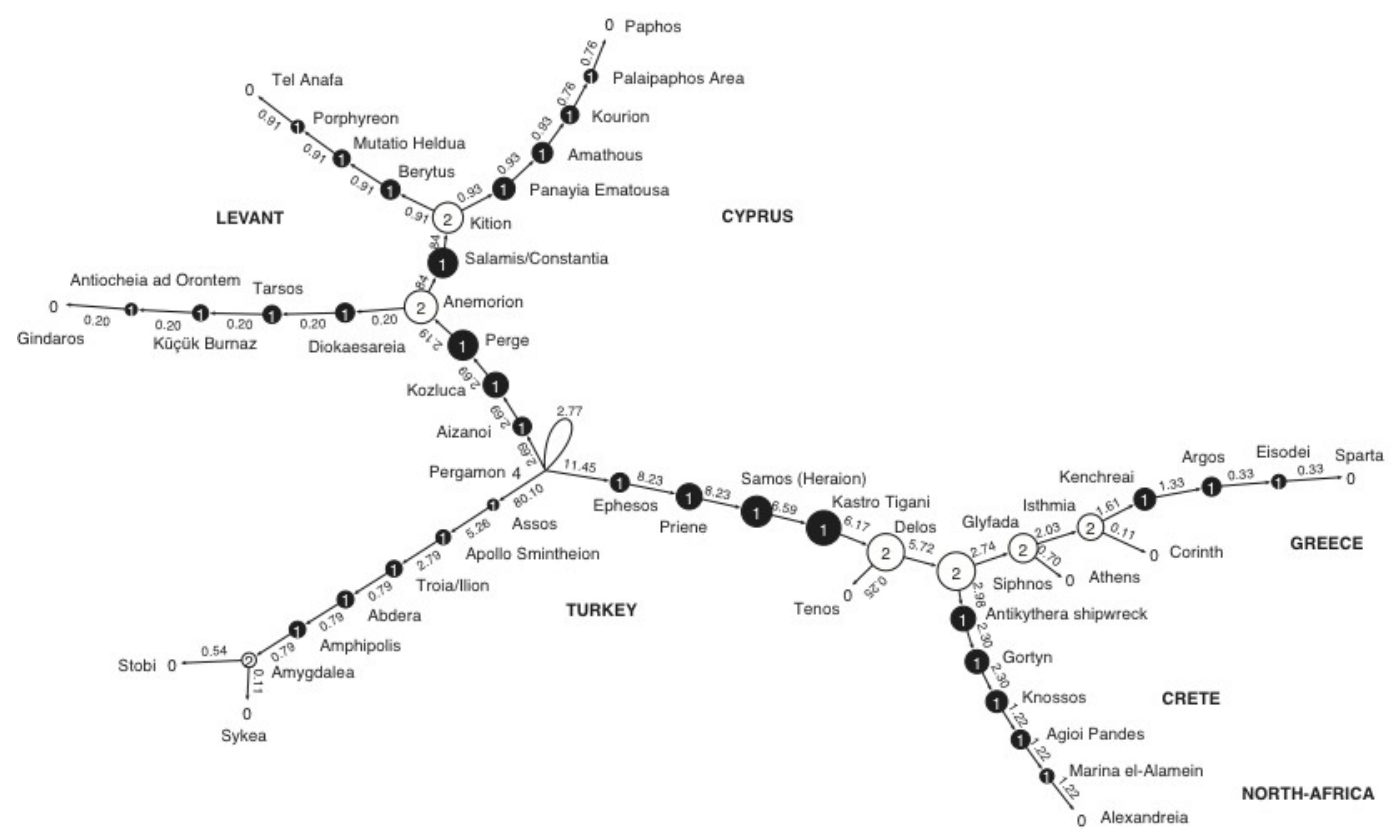

Figure 11

Distance network of the period 50-25 BC representing the transportation of Eastern Sigillata C table ware sherds from their place of production (Pergamon) to their place of deposition (all other nodes).

The arcs and their numbers represent the accumulated estimated volume of sherds that was transported between two sites. The colour and number of vertices represents their outdegree. The size of vertices indicates their betweenness centrality value. Modern place names (in bold) were added as a geographical reference.

\begin{tabular}{|c|c|c|c|c|}
\hline ICRATES table & Catalogue table & Location table & Deposit table & Publication table \\
\hline ICRATES unique ID & ICRATES unique ID & Site name & Deposit ID & Publication ID \\
\hline Catalogue unique ID & Catalogue unique ID & $\begin{array}{c}\text { Ancient and modern } \\
\text { names }\end{array}$ & $\begin{array}{l}\text { Archaeological } \\
\text { context }\end{array}$ & Author \\
\hline Publication & Fabric & $\begin{array}{c}\text { Environmental } \\
\text { features }\end{array}$ & Deposit date & Year \\
\hline Location & Form & Modern country & Type of deposit & Reference \\
\hline Deposit & Stamps & Roman province & Ceramic objects & Year(s) of activity \\
\hline Functional category & Measurements & Distance to sea & Published notes & Nationality team \\
\hline & $\ldots$ & $\ldots$ & $\ldots$ & $\ldots$ \\
\hline
\end{tabular}

Table 1

Summary of the information stored in the main tables of the ICRATES database. 


\begin{tabular}{|c|c|c|}
\hline Ware & $\begin{array}{l}\text { Typo-chronological } \\
\text { reference }\end{array}$ & Region of production \\
\hline Eastern Sigillata A & Hayes 1985 & $\begin{array}{l}\text { Coast between Tarsos } \\
\text { (TUR) and Latakia } \\
\text { (SYR) }\end{array}$ \\
\hline Eastern Sigillata B & Hayes 1985 & $\begin{array}{l}\text { Maeander Valley in } \\
\text { western Asia Minor } \\
\text { (TUR). Possibly Aydin } \\
\text { (ancient Tralleis) }\end{array}$ \\
\hline Eastern Sigillata C & $\begin{array}{c}\text { Meyer-Schlichtmann } \\
1988\end{array}$ & $\begin{array}{l}\text { Pergamon and } \\
\text { surrounding region }\end{array}$ \\
\hline Eastern Sigillata D & Hayes 1985 & $\begin{array}{l}\text { Cyprus (probably the } \\
\text { western part) }\end{array}$ \\
\hline Italian Sigillata & Ettlinger et.al. 1990 & $\begin{array}{c}\text { Southern France (Lyon) } \\
\text { and Italy }\end{array}$ \\
\hline
\end{tabular}

Table 2

Typo-chronological reference, presumed region of production and possible centres of production for all major wares included in the analysis. 


\section{FOOTNOTES}

1. http://www.arts.kuleuven.be/icrates/. 